\title{
Self-evaluation in Dialysis Patients
}

\author{
K. Bargiel-Matusiewicz ${ }^{1}$, A. Sobota ${ }^{1}$, A. Wilczynska ${ }^{2}$ \\ ${ }^{1}$ Faculty of Psychology, Warsaw University, Warsaw, Poland; ${ }^{2}$ Faculty of Psychology, Silesian University, Katowice, Poland
}

\begin{abstract}
Objective: The aim of this study is to present the results of a self-reported evaluation of the psychoemotional status by dialysis patients. The level of self-esteem influences the emotions felt, both positive and negative, which in turn may determine the adherence to treatment instructions, and which certainly is reflected in the somatic condition.

Material and methods: The study was a randomized controlled trial using a sample of 102 fully informed and consenting patients with end-stage renal disease and 102 people from the general population. The survey instrument used was a Self-Esteem Inventory.

Results: The results show that there were differences between the dialysis patients and the general population concerning Physical Self-Esteem and Acting/Task Self-Esteem. The patients scored significantly lower than the healthy subjects lower on both subscales. No differences were noted between the two groups of subjects regarding of Social Self-Esteem and Emotional Self-Esteem. The results also show that the level of self-esteem in dialyzed patients under the age 50 years was higher than in those above 50 regarding the sociability, sense of humor, memory, and the sense of being accepted by others.

Conclusion: We conclude that there are differences in the self-reported level of self-esteem between dialyzed patients and the general population. The patients' age also factors in the self-reported assessment.
\end{abstract}

Key words: well-being, self-esteem, dialysis patients

\section{INTRODUCTION}

The aim of this study is to present the results of a self-reported evaluation of self-esteem and social functioning in dialyzed patients. According to the World Health Organization, health cannot merely be defined as the absence of disease, but as a state of complete physical, mental, and social well-being [1]. Therefore, it seems that the above mentioned variables play a role when it comes to securing well-being. The level of self-esteem influences the emotions felt, both positive and negative, which in turn may determine the adherence to treatment instructions [2] and which certainly is reflected in the somatic condition of the sick. However, self-esteem not only determines the feeling of positive emotions, but also influences acceptance of challenges, which is important in the case of a sick person. The lack of will to face challenges is most of- ten connected with resignation and surrender to disease.

Brownbridge and Fielding [3] showed a significant dependence of the essential indicators of the somatic condition in dialyzed patients, namely the levels of potassium, blood pressure, urea, or weight gains between dialyses, on psychosocial factors, in particular on the level of depression and anxiety. The significance of mood for observing doctor's advice, e.g., concerning the diet, is stressed by many authors [4-7]. McDade-Montez et al [8] found that in the period of up to 4 years from the occurrence of depressive symptoms, $18 \%$ of patients who require dialyses resigned from them.

Limitations resulting from the treatment procedure and a subjective perception of the situation may also have a negative influence on fulfilling social roles. Parkerson and Gutman [9] indicated, in a study that referred mostly to dialyzed patients, that depression and anxiety are primary factors contributing to the occurrence of disability more than the heaviness of somatic disorder.

The problem of the mental condition of patients dialyzed in Poland seems not only interesting but also important. There is no accurate data on the number of Polish hospitals which employ psychologists; however, bearing in mind constant problems of the public health care, it may be assumed that the percentage is small. It means that the optimal psychological care and support are still not provided for the Polish patients. Thus, in the present study we set out to determine the self-esteem of dialyzed patients, on the basis of selfreports, and to compare the results with those obtained in a group of healthy persons.

\section{MATERIAL AND Methods}

The study was performed in accordance with the Declaration of Helsinki for Human Research and was approved by a local Ethics Committee. We conducted a cross-sectional study at the Dialysis Unit of a Warsaw University Hospital; 102 dialyzed patients (F/M 44/58; aged 28-72) were enrolled into the study. The average length of renal replacement therapy in the group of dialyzed patients was 4.4 years. In the second part of the study, the same psychometric measures were used in 108 healthy persons recruited from the general population, working in a few institutions in Warsaw, which constituted a reference group (F/M 58/50; aged 26-70). 


\section{Measures And Questionnaires}

The psychometric tool used in the study was a Self-Esteem Inventory, developed by Heszen-Niejodek [10]. The questionnaire consists of 18 items. Participants responded on a 7 -point Likert-type scale; from 1 - the lowest to 7 - the highest intensity of a given factor. The results were analyzed taking into account a total score of the questionnaire and the individual scores representing the subscales for the following self-assessment factors: the Physical Self (including: physical fitness, attractive appearance, and health), the Emotional Self (including: self-control, inner peace, ability to solve conflicts, and understanding of others), the Task-related Self (including: diligence, persistence, responsibility, and perceptivity), and the Social Self (including: popularity, sense of humor, social ability, friendliness, and being accepted by others). The questionnaire displays a substantial internal consistency and reliability, as judged from the Cronbach alpha coefficient of 0.87 .

Data are presented as means of raw scores \pm SD. An unpaired t-test was used for the comparison between dialyzed patients and healthy subjects. The SPSS 14.0 statistical package for Windows was used for the statistical elaboration.

\section{RESULTS}

Table 1 shows the differences between the dialyzed and healthy persons in terms of the general self-esteem and the four factors outline above in the self-esteem questionnaire. When the whole scale was taken into consideration no differences in the self-esteem assessment could be substantiated between the dialyzed patients and healthy subjects. However, significant differences appeared in a separate analysis of the subscales for Physical Self $(\mathrm{P}<0.001)$ and Task-Related Self $(\mathrm{P}<0.005)$; to the advantage of healthy persons who achieved better results in both cases. Yet, no differences were found between both groups of subjects concerning Social Self and Emotional Self.

Additionally, detailed comparison regarding all factors included in the subscales describing self-esteem between dialyzed patients and healthy subjects was then conducted. Healthy persons scored significantly better in diligence, persistence, physical fitness, responsibility, and health than the group of dialyzed patients (Table 2). Furthermore, the dialyzed patients who were younger than 50 years of age scored significantly better in the self-esteem evaluation than the older patients did (Table 3).

\section{Discussion}

The results of the present study demonstrate that certain aspects of dialyzed patients' self-esteem are different than those in healthy people. Of note, patients self-report their physical health and fitness worse than healthy subjects do. Also other factors essential in shaping the self-esteem, such as persistence, diligence, responsibility are downgraded inpatients. However, they rate their attractiveness and perceptivity at the levels similar to those in healthy persons. These find-
Table 1. Self-esteem reported by dialyzed patients and healthy subjects.

\begin{tabular}{llll}
\hline Variable & Dialyzed & Healthy & $\mathrm{P}$ \\
\hline General & $86.4 \pm 14.5$ & $88.7 \pm 13.1$ & 0.27 \\
Physical Self & $\mathbf{1 0 . 3} \pm \mathbf{3 . 8}$ & $\mathbf{1 3 . 0} \pm \mathbf{3 . 2}$ & $\mathbf{0 . 0 0 1}$ \\
Task-Related Self & $\mathbf{1 9 . 9} \pm 4.7$ & $\mathbf{2 1 . 6} \pm \mathbf{3 . 5}$ & $\mathbf{0 . 0 0 5}$ \\
Emotional Self & $19.9 \pm 4.1$ & $19.6 \pm 3.9$ & 0.71 \\
Social Self & $24.5 \pm 5.8$ & $5.8 \pm 4.8$ & 0.76 \\
\hline
\end{tabular}

Data are means of raw scores \pm SD.

Table 2. Differences in the factorial analysis of self-esteem subscales between dialyzed patients and healthy subjects.

\begin{tabular}{lccc}
\hline Factors & Dialyzed & Healthy & $\mathrm{P}$ \\
\hline Perceptivity & $5.0 \pm 1.6$ & $4.7 \pm 1.4$ & 0.21 \\
Diligence & $4.6 \pm 1.8$ & $5.4 \pm 1.3$ & $\mathbf{< 0 . 0 0 1}$ \\
Physical fitness & $3.5 \pm 1.8$ & $4.2 \pm 1.5$ & $\mathbf{< 0 . 0 0 5}$ \\
Sociability & $4.9 \pm 1.7$ & $4.8 \pm 1.6$ & 0.69 \\
Persistence & $4.8 \pm 1.6$ & $5.2 \pm 1.4$ & $\mathbf{< 0 . 0 5}$ \\
Ability to solve & & & \\
conflicts & $4.8 \pm 1.5$ & $4.9 \pm 1.3$ & 0.55 \\
Sense of humor & $5.1 \pm 1.6$ & $5.2 \pm 1.3$ & 0.73 \\
Responsibility & $5.4 \pm 1.4$ & $6.3 \pm 0.9$ & $<\mathbf{0 . 0 0 1}$ \\
Popularity & $4.0 \pm 1.7$ & $3.9 \pm 1.6$ & 0.77 \\
Memory & $5.0 \pm 1.6$ & $4.7 \pm 1.4$ & 0.08 \\
Friendliness & $5.4 \pm 1.5$ & $5.4 \pm 1.2$ & 0.81 \\
Self-control & $4.8 \pm 1.6$ & $4.9 \pm 1.5$ & 0.54 \\
Being accepted by & & & \\
others & $4.9 \pm 1.5$ & $4.9 \pm 1.2$ & 0.94 \\
Health & $2.9 \pm 1.5$ & $4.6 \pm 1.3$ & $<\mathbf{0 . 0 0 1}$ \\
Understanding others & $5.3 \pm 1.7$ & $5.2 \pm 1.1$ & 0.94 \\
Inner peace & $4.6 \pm 1.6$ & $4.5 \pm 1.4$ & 0.49 \\
Attractive appearance & $3.8 \pm 1.6$ & $4.1 \pm 1.4$ & 0.12 \\
Intelligence & $4.9 \pm 1.3$ & $5.1 \pm 1.1$ & 0.30 \\
\hline
\end{tabular}

Data are means of raw scores \pm SD.

Table 3. Age-dependence of self-esteem in dialyzed patients (Mann-Whitney U).

\begin{tabular}{lccc}
\hline Variables & \multicolumn{2}{c}{ Dialyzed patients } & $\mathrm{P}$ \\
& Aged $\leq 50$ & Aged $\geq 50$ & $<0.05$ \\
\hline Sociability & 61.9 & 45.0 & $<0.05$ \\
Sense of humor & 62.3 & 45.6 & $<0.05$ \\
Memory & 59.7 & 44.9 & $<0.05$ \\
$\begin{array}{l}\text { Being accepted by } \\
\text { others }\end{array}$ & 58.6 & 45.9 & $<0.05$ \\
Social Self & 50.1 & 48.1 & $<0.05$ \\
\hline
\end{tabular}

ings point out that dialysotherapy influences self-image. Despite the fact that dialysis has a number of beneficial and restorative health functions, patients perceive themselves as less healthy and less fit when compared with the rest of the population. 
The fact that dialyzed patients evaluate their persistence, diligence and responsibility as lower, may have a detrimental influence on their performance in many tasks of life, not only associated with their health, but also with performing different professional roles. A negative evaluation of the afore-mentioned predispositions also may intensify occupational stress, which, in turn, often is associated with an early exit from the labor market. Many studies point to the problem of dialyzed patients' exit from professional life. Low self-esteem may surely contribute to that. Moreover, resignation from professional tasks may worsen the financial status and lead to further consequences, such as the necessity to change the lifestyle or habits, or resignation from hobbies [11]. It also is worth noting that no differences were observed between patients and healthy persons in terms of self-esteem having to do with cognitive processes, such as perceptivity and memory. Here, the dialyzed patients rated themselves similarly to healthy persons, which is contrast to other works showing that the dialyzed persons achieve lower results on the objective scales of cognitive functioning [12]. The discrepancy may stem from not realizing by the patients of the present study disturbances in their cognitive functioning or they were using psychological defense mechanisms such as denial repression which enable blocking or removing unpleasant information from consciousness.

The present study shows that the dialyzed patients younger than 50 years old fare better than older patients. One of the reasons for a better self-esteem in younger patients may be the cultural changes taking place in many European countries. We may talk here about a remarkable technological progress, shaping flexible attitudes, access to different information or various activities. If these differences are indeed connected with social and cultural changes, than probably the level of social adaptation and professional activity in dialyzed patients, particularly in younger ones, will increase. There are studies, however, which point to the opposite, i.e., that younger age is an adverse predictor an adverse predicator in following doctor's prescriptions by hemodialyzed patients; the younger the patient, the lower the readiness to cooperate with a doctor [13].

To sum up, dialyzed patients have a lower self-esteem related to the body, physicality, and the ability to act and achieve goals.

Acknowledgements: This project was realized at the Faculty of Psychology, Warsaw University in Warsaw, Poland and was supported by the Polish Ministry of Science and Higher Education.

Conflicts of interest: No conflicts of interests were declared by the authors in relation to this article.

\section{REFERENCES}

1. Men Ageing and Health. World Health Organization 2001.

2. Drayer R, Piraino B, Reynolds C, Houck P, Mazumdar S, Bernardini J, Shear M, Rollman B. Characteristics of depression in hemodialysis patients: Symptoms, quality of life and mortality risk. Gen Hosp Psychiatry 2006; 28 : 306-12.

3. Brownbridge G, Fielding DM. Psychosocial adjustment and adherence to dialysis treatment regimes. Pediatr Nephrol 1994; 8: 744-9.

4. Bargiel-Matusiewicz K. Psychological influence on the psychical state of hemodialysis patients. J Physiol Pharmacol 2006; 57 Suppl 4: 33-8.

5. Barnett T, Li Yoong T, Pinikahana J, Si-Yen T. Fluid compliance among patients having hemodialysis: Can an educational programme make a difference? J Adv Nurs 2008; 61: 300-6

6. Everest KD, Brantley J, Sletten C, Jones GN, McKnight GT. The relation of stress and depression to interdialytic weight gain in hemodialysis patients. Behav Med 1995; 21: 25-30.

7. Tsay SL, Lee YC, Lee YC. Effects of an adaptation training programme for patients with end-stage renal disease. J Adv Nurs 2005; 50: 39-46.

8. McDade-Montez EA, Christensen AJ, Cvengros JA.The role of depression symptoms in dialysis withdrawal. Health Psychol 2006; 25: 198-204.

9. Parkerson GR, Gutman RA. Perceived mental health and disablement of primary care and end-stage renal disease patients. Int J Psychiatry Med 1997; 27: 33-45.

10. Heszen-Niejodek I. Stress and coping - the main controversies. In: Man In Stress. Heszen-Niejodek I, Ratajczak Z (eds.), Katowice, Publishing House US, 2000.

11. Timmers L, Thong M, Dekker FW, Boeschoten EW, Heijmans M, Rijken M, Weinmam J, Kaptein A. Illness perception in dialysis patients and their association with quality of life. Psychol Health 2008; 23: 679-90.

12. Kurella M, Chertow GM, Fried LF, Cummings SR, Harris T, Simonsick E, Satterfiels S, Ayonayon H, Yaffe K. Chronic kidney disease and cognitive impairment in the elderly: The health, aging, and body composition study. J Am Soc Nephrol 2005; 16: 2127-33.

13. Hailey BJ, Moss SB. Compliance behaviour in patients undergoing hemodialysis: A review of the literature. Psychol Health Med 2000; 5: 395-406.

Address for correspondence:

Kamilla Bargiel-Matusiewicz

Faculty of Psychology

Warsaw University

5/7 Stawki St.

00-183 Warsaw

Poland

Phone: +48 225549703

E-mail:k.matusiewicz@op.pl 